


\begin{tabular}{|c|c|c|c|}
\hline$\Omega$ & D & $\equiv$ & (2) \\
\hline $\begin{array}{l}\text { Ali Merzouk', } \\
\text { Pascal Kurosinski², } \\
\text { Konstantinos } \\
\text { Kostikas }^{3}\end{array}$ & $\begin{array}{l}\text { 'ERS e-Learning Coordinator, } \\
\text { Lausanne, Switzerland } \\
{ }^{2} \text { ERS Senior e-Learning Coordinator, } \\
\text { Lausanne, Switzerland } \\
\text { 'ERS Learning Resources Director, } \\
\text { 2nd Respiratory Medicine } \\
\text { Department, National and } \\
\text { Kapodistrian University of Athens, } \\
\text { Athens, Greece }\end{array}$ & $\begin{array}{l}\text { Konstantinos Kostikas, 2nd } \\
\text { Respiratory Medicine } \\
\text { Department, National and } \\
\text { Kapodistrian. University of } \\
\text { Athens, Athens } 12462 \text {, } \\
\text { Greece }\end{array}$ & ktk@otenet.gr \\
\hline
\end{tabular}

\section{e-Learning for the medical team: the present and future of ERS Learning Resources}

\section{Introduction: definition, history and basic principles of e-learning}

The term "e-learning" is a comprehensive concept that involves the use of all kinds of electronic media and information and communication technology in education. The broad concept of e-learning in general includes the implementation of all kinds of educational technology in learning and teaching procedures, including online learning and computer-delivered instructions.

The foundations of modern e-learning were laid down in 1953-1956 by Burrhus Frederic Skinner (fig. 1) who developed the radical behaviourism theory. Skinner invented the operant conditioning chamber and constructed the first teaching machine which simply presented problems in random order to the learner and gave feedback after each response. In the following years, he developed early computer-based training (CBT) programmes that followed the idea of "programmed instruction" [1], in which material was carefully sequenced in small parts to build a systematic process of descriptions, questions and answers. Skinner's early teaching machines had substantial limitations. For example, while learners were rewarded for correct responses, they received no feedback or explanation when their responses were incorrect.

In 1960, Norman Crowder tried to solve this problem with a technique called "intrinsic programming". The basic principle of this approach was that the learner's responses determined which material was subsequently presented. At the end of each section, a multiple-choice question was presented to

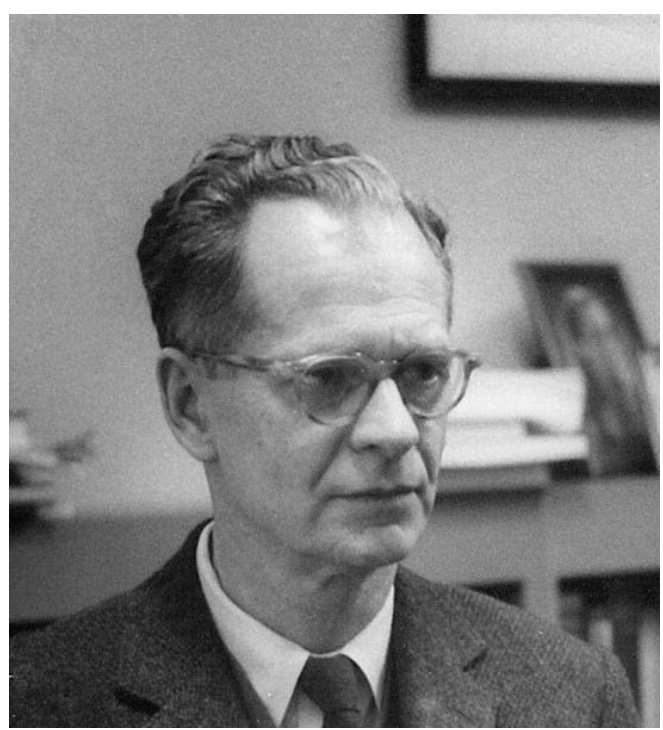

Figure 1

B.F. Skinner: an early pioneer of e-learning. Image: Silly rabbit, Wikimedia Commons under CC BY-3.o.
Statement of Interest

A. Merzouk and

P. Kurosinski are employees of ERS 
the learner and each choice was linked to another section. If the learner's response was correct, new material was presented. If it was incorrect, review or reinforcement material was presented [2]. Another early computerassisted instruction system called PLATO (Programmed Logic for Automated Teaching Operation) was developed in 1960 at the University of Illinois (Champaign, IL, USA). The "PLATO compiler" allowed the development of various forms of "teaching logic" and was the first authoring system for developing computer-based lessons and courses [3].

In the middle of the 1990s, the growth of the internet opened new e-learning possibilities. Web-based training (WBT) became the dominant branch of e-learning. The major advantage of web-based training compared with computer-based training is the centralised content distribution, which reduces the costs and allows easy updating of the material. Several other factors supported the spread of e-learning in the new century, including the wide availability of computers and portable devices (including smartphones and tablets), the familiarisation of teachers with information and communication technology, the increased technological expectations of learners and the wide spectrum of educational opportunities, including multimedia presentations and simulation activities [4].

\section{e-Learning methodologies}

There are two major branches of e-learning: self-directed and instructor-led e-learning. Self-directed e-learning involves learners who manage their educational activity independently, while instructor-led e-learning provides different levels of support from teachers or tutors and often allows collaboration among learners. The advantage of selfdirected learning is that it allows learners to work at their own pace and choose their learning paths based on their personal needs and preferences. An instructor-led approach is usually based on a linear curriculum that integrates the activities into a chronological course or a syllabus.

Regarding the timing of information exchange, e-Learning can be synchronous or asynchronous. The advantage of synchronous elearning is the ability to exchange information in real time among broader groups of people and the opportunity to provide immediate feedback in a collaborative manner. Asynchronous elearning provides the opportunity for learners to use the platform at their own chosen time. The asynchronous approach is less collaborative but may prove convenient in medicine, as clinical responsibilities of busy clinicians often do not allow them to follow strict timelines.

Instructor-led e-learning is often organised with synchronous activities using webinars or virtual classrooms. This approach more closely resembles traditional classroom learning and, in this case, the shared environment allows instructors and multiple learners to collaborate and discuss in real time. There are a growing number of texts outlining the potential benefits of web-based training and the use of multimedia $[5,6]$, but there are only a few reported studies that address synchronous e-learning programmes in medical education [7].

Several terms have been used to describe distinctive roles in e-learning activities [8]. The majority of these roles need to be identified in each successful activity (see box).

A crucial issue in the e-learning process is the matching of the content that is provided online with the involvement of the participants. An attractive and easy-to-navigate environment in combination with effective guidance is crucial to this process. This is extremely important in activities directly related to the provision of certificates and CME/CPD credits. It is always important to bear in mind that learners are not always familiar with the specific process and constant support should be available.

\section{Online teaching}

A central role in e-learning procedures is that of the individual(s) who guide and focus the learning activities to the specific targets that need to be accomplished by the learners. The availability of information technology tools alone does not automatically turn students into effective learners. Modern e-learning requires competent and actively involved online teachers and instructors who will be able to achieve engaging and learner-centred activities, and encourage interaction, collaboration and communication $[8,9]$.

While in-classroom teaching with face-toface communication allows clear understanding between teachers and learners, such direct communication is typically unavailable with 


\section{e-Learner}

This refers to any individual involved in learning activities online. The e-learner is, in general, more independent than the traditional face-to-face learner and may be involved in only selected parts of the activity. The feedback to the rest of the community may be provided by all the modern means of electronic interaction, including e-mail, social networking or peer-to-peer communication.

\section{e-Teacher}

The e-teacher is the person responsible for the development of the content and the supervision of the learning activity. In contrast with the teaching skills required for a "traditional" teaching role, there is an increased need for this person to have special information and communication technology skills. There is also a need for long-term engagement, due to the fact that e-learning activities are often valid for a long time after they are launched. There are significant issues that need to be addressed, including difficulties in the recognition and reimbursement of the time invested in such activities.

e-Technologist

The involvement of qualified professionals is central for the design, facilitation and support of e-learning activities. Besides their role in the technical part of the development of the activity, they need to be able to effectively balance what is desired by the e-teacher and what is technologically feasible.

\section{$e$-Logistics and administration}

Several important issues, including financing and timetabling, need to be addressed for each successful activity. The administrative role in e-learning begins with the tracking of learners' involvement and involves additional quality assurance and audit issues.

\section{$e$-Assessment}

The e-learners' performance needs to be formally assessed, both during and at the end of the course. This part also involves the provision of certificates and continuous medical education (CME) or continuous professional development (CPD) credits. e-Assessment may involve traditional methods (e.g. multiple-choice questions) or more comprehensive methods (e.g. virtual patient cases or performance in medical simulators). An important issue in this process is the verification of the actual participation of the person(s) involved in the activity.

e-Community support

e-Community support involves the dissemination of information and knowledge and is made possible with a broad community of learners. This may involve social networking, blogging or file sharing and may speed-up the learners' involvement in the medical community. It is important that security and copyright issues are clarified for this activity.

e-learning. This teacher/instructor-learner relationship has to be carefully mediated by technology throughout the process of teaching and learning [10]. Technology cannot always substitute for physical guidance in making learners achieve learning outcomes. There is a vast set of online technologies that can be used to enhance online teaching in medical education. However, the implementation of information technology needs to be based on sound educational approaches. Theories of adult learning applied in face-to-face settings can also be applied in online teaching with some adaptation inherent to the online teaching context [9].

Three key factors have been described for achieving successful e-learning [11]:

\section{Fostering learner engagement}

- An attractive online interface is an important aspect of the e-teaching/e-learning process, as it represents the first interaction that is provided to the learners. It is of critical importance not to overload the senses of learners with useless artefacts, in order to avoid distraction from the learning procedure.

- A primary goal in the attempt to ensure engagement of the people involved in an e-learning activity is to create a community of learners. This is typically relevant to medical education, as the purpose of medical teaching is not only supporting learners to take their place in the workforce (the "Does" on Miller's Pyramid of Clinical Competence [12]) but also to be part of the medical community [10]. It is essential to facilitate knowledge exchange between peers and also between learners and teachers. The aim is to provide access to diverse resources and stimulate knowledge creation by the community.

- Another principle relevant to medical education is based on the behaviourist 
approach [13]. Learning objectives and outcomes should be stated clearly from the beginning, together with the methods to be used in order to achieve these goals as well as the prerequisites. Learning outcomes can again be refined using Miller's pyramid. This helps the learner step efficiently from the uncertainty zone to the learning process.

- Finally, the e-learning environment should be flexible in order to allow for personalised use. Learners have different learning styles and different ways to interact with content. Hence, resources should be made available in different formats in order to adapt to the individual styles and needs.

\section{Stimulating intellectual development}

Medical education involves not only knowledge but also skills and attitudes. This starts with a careful investigation of the background of the target group, followed by proper stimulation of the individual involvement. Useful assets of this process include:

- Setting and targeting specific tasks that stimulate the learning process. Tasks should be designed with the presumption that the learner is not tabula rasa (i.e. not coming from a position of complete ignorance) [10] but instead has a significant background of basic knowledge. Teachers should pay attention to move gradually from simpler to more complex tasks by bridging between new and existing knowledge, at least at the beginning of the process.

- Development of a "natural" clinical learning environment, including case-based learning that is typically more relevant to medical education, may stimulate learners by involving them in "real-life" patient scenarios [10]. Doctors can then connect the activity to their previous clinical experience and apply the content in their practice. In medical education, reflection is critical. The e-teacher could use online tools to make learners search, reflect on clinical practice and discuss results with peers [14].

- An online assessment system is paramount for the learning process. Continuous assessment will define the style to be adopted by learners: surface learning or deep and profound learning including reasoning and reflection [7]. In medical education, learners should both be able to recall facts, but also understand the complexity and to apply the obtained knowledge in different settings while adopting the right attitudes. In that sense, it is imperative to apply the basic principle that "assessment drives learning" [10].

\section{Building rapport with learners}

Personal contact between the teacher and each individual learner is an important task for online teachers to create a social presence. One way to establish personal relationships can be by sharing personal experiences or by the use of humour or emoticons.

\section{New developments and trends}

During the past few years a variety of new developments and trends has been implemented in e-learning activities:

\section{Blended learning}

Blended learning is an important trend for distance learning, involving a mixture of traditional face-to-face and e-learning activities, in which the online portion serves as an extension of traditional classroom learning. However, several other definitions of blended learning have been used, including a mixture of instructional technologies (e.g. virtual classroom, self-paced instruction, collaborative learning, streaming video, audio and text), or as a combination of various pedagogical approaches, including constructivism, behaviourism or cognitivism.

\section{Mobile learning}

Mobile learning addresses the increasing capabilities of mobile electronic devices, i.e. smartphones and tablets. The objective of mobile learning is to provide access to education to the individual user anywhere and at any time.

\section{Microlearning}

Microlearning is a recent trend in social learning which breaks up the educational content into small units that can be quickly 
completed. Microlearning is often based on quiz questions and flash cards that can be used either individually or as parts of a broader educational concept.

\section{Social learning}

The social learning theory by Albert Bandura (fig. 2), goes back to the 1970s, stating that behaviour is learned primarily by observing and imitating others. This type of learning can be covered in today's e-learning through the use of information exchange via social media channels like Twitter or Facebook.

\section{Simulators}

Simulation-based e-learning requires the learner to respond to simulated situations as they would do in in real life. Simulation-based education can be delivered in medicine in a variety of formats, including virtual patients, computer-based physiology simulators or advanced technology simulators (e.g. ventilators or pulmonary function testing equipment in respiratory medicine).

\section{Gamification}

Gamification is most often defined as the use of gameplay mechanisms in the educational process to pro-actively engage the learners. The gamification strategy often uses rewards for learners who accomplish desired tasks or motivates competition between learners.

\section{Personalised learning environments}

Personal learning environments (PLE) refer to a set of tools and spaces defined by the user in order to make the best of his/her individual educational experience. This definition is similar to the one stated by the non-profit e-learning advocacy association EDUCAUSE (2009): "The term personal learning environment (PLE) describes the tools, communities, and services that constitute the individual educational platforms learners use to direct their own learning and pursue educational goals" [15].

Is PLE a system, a set of technological software or a concept? Several theoretical approaches try to delimit the conceptual framework of such a new paradigm. Some

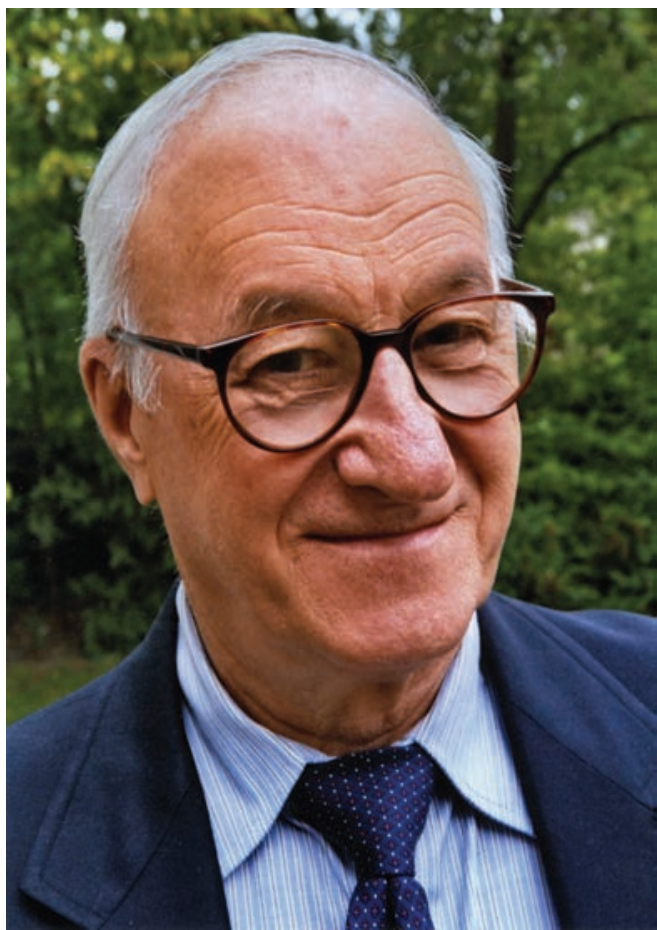

Figure 2

Albert Bandura: his social learning theory stated that behaviour is learned through observation and imitation. Image: Albert Bandura, Wikimedia Commons under CC BY-SA 4.o.

of these define it as an idea that integrates what is now occurring in the field of learning/ education and new approaches to learning, lifelong learning and learning styles. This was highlighted by ATTWELL [16]: "Important concepts in PLEs include the integration of both formal and informal learning episodes into a single experience, the use of social networks that can cross institutional boundaries and the use of networking protocols (peer-to-peer, web services, syndication) to connect a range of resources and systems within a personallymanaged space". The idea behind a PLE involves a paradigm shift from a teachercentred to a learner-centred approach, in which learning tools and environment are controlled by the user. Similarly, DREXLER [17] and VälJATAGA and LAANPERE [18] define the development of PLEs as a learning process and outcome constructed and driven by learners.

\section{Features of the PLE}

During the last decade, virtual learning environments, such as learning management systems (LMS), have played a prominent role 
in e-learning schemes. On these types of platforms, the teacher plays an important role in the teaching/learning process. The LMS provides the tools needed to perform the tasks, but this therefore limits the functionality to distributing learning units, controlling content, providing assessments and tracking learning [19]. A PLE is a typical response to the expansion of learning needs and networked information technologies. Coupled with the development of a new era of web services and tools, ubiquitous computing and social software, the learning process is supposed to be driven by the user within an environment designed for such a purpose. "The most compelling argument for the PLE is to develop educational technology which can respond to the way people are using technology for learning and which allows them to shape their own learning spaces, to form and join communities, and to create, consume, remix and share material" [20].

\section{e-Portfolios}

Personalised e-learning achievements may then be included in the individual's e-Portfolio. An e-Portfolio can be defined as: "...a purposeful aggregation of digital items [ideas, evidence, reflections, feedback etc.] which 'presents' a selected audience with evidence of a person's learning and/or ability" [21]. Driven not only by legal processes of revalidation and recertification but also by self-regulation considerations, medical doctors will have to demonstrate continuous

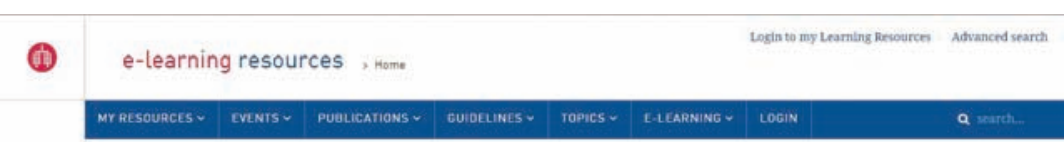

ERS e-Learning Resources
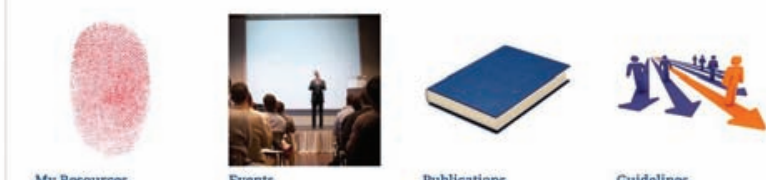

My Resources

Events

Guidelines
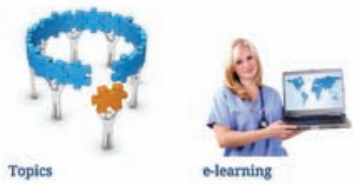

Figure 3

The ERS e-Learning Resources home page at www.ers-education.org ability in their field of practice. Moreover, medical practice is challenged to evolve towards a competency-based approach to learning where skills and attitudes, in addition to knowledge, will play a prominent role. Simultaneously, assessment strategies and methods are now developed to track learners' abilities in different context settings and over various periods of time $[22,23]$. In this context, e-portfolios can be a robust tool to record evidence of achievements, developments and reflections on practice by storing them in a private space and showing them when needed. Another argument for e-portfolios is that paper-based portfolios are gradually being replaced by digital portfolios thanks to the hyper-linking features that make it easy to connect and navigate between the components of e-portfolios. In a similar way, aggregation of information and customisation of viewing is accessible within a few clicks.

\section{ERS e-Learning Resources and possible applications}

ERS has recently developed in the Learning Resources website (fig. 3; available at www. ers-education.org) a dedicated space called My Learning Resources. Upon login, ERS Members have access to an individual page where they can configure their related fields of interest and get resources based on their profile. The space includes a certain number of services such as new content, bookmarks, upcoming courses and browser history. The content includes a wide variety of types of information in the broad area of respiratory medicine, in various formats in a user-friendly interface. Alongside the popular sections of congress and meetings material, guidelines, procedure videos and case reports, a new section of simulators has recently been added to expand the content of the ERS e-Learning Resources (fig. 4).

This configuration will be enriched with a PLE based on digital tools and services that could be beneficial for members in their daily learning activities, professional development, publications and peer review activities. This centralised environment has to be task based and carefully studied in a way to respond to and anticipate an individual user's needs and not only be populated with useless generic tools. Collaborative construction of knowledge, 

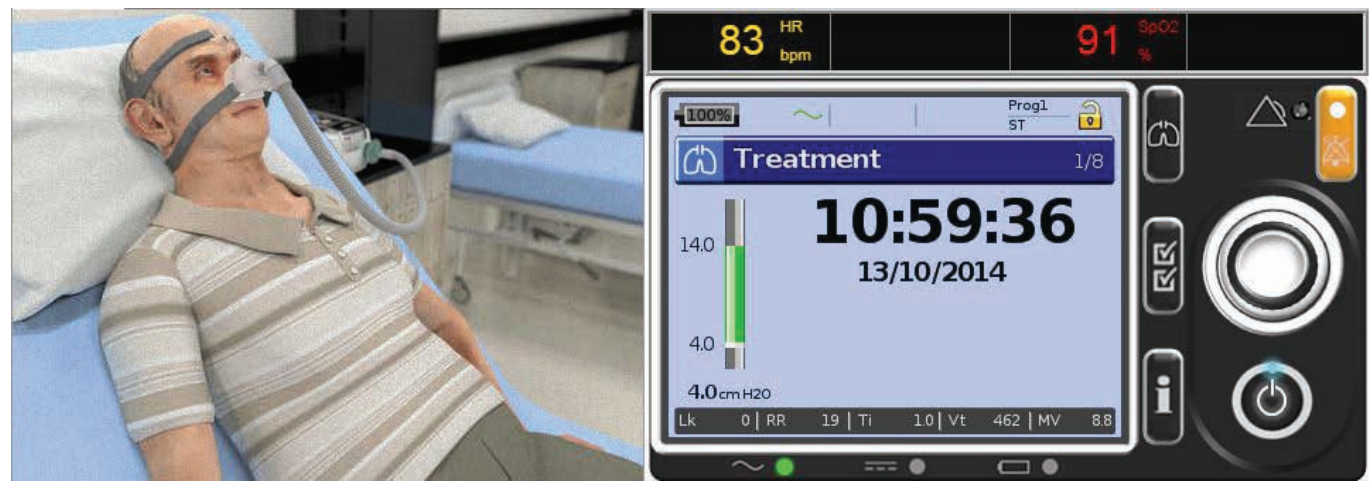

Figure 4

Simulated noninvasive ventilation treatment on the ERS e-Learning website.

collective critical thinking and metacognition should be particularly encouraged, as learning cannot be disconnected from its social component [24].

A possible item that could be added to such a dashboard is tools to collaborate in Respipedia, the upcoming ERS respiratory wiki. Additionally, a robust and versatile learning management system is also needed in order to design and manage learning processes and assessments. The cornerstone of this environment is the developing ERS e-Portfolio, a personalised approach that will allow ERS members to record, keep track and organise learning activities and achievements, store CME credits and certificates, and display them properly to third parties for professional development needs.

\section{Conclusions and future prospects}

In the past few years, e-learning has changed the way we look at medical training, based on both the acquisition of knowledge and the development of new skills. The development of new technologies and novel portable multimedia devices has led to a rapidly expanding area that provides learners with multiple different choices. The most important asset of modern e-learning is the fact that it allows the individual users to tailor the learning experience to their personal educational needs in a practical manner with significant flexibility to their time availability; time is the largest deficit of the busy clinicians of modern medicine. In that sense, a simple, comprehensive and consistent environment is required for the provision of high standards and, at the same time, a costand time-effective educational experience. The modern way to do this is through a user-friendly e-portfolio that can both organise and plan e-learning activities and also collect the accomplished learning tasks in a manner that can be easily retrievable and ready to demonstrate to all interested parties. The current rise in e-learning's popularity is expected to expand further and ERS is certainly on track to facilitate continued education in the respiratory field.

\section{References}

1. Skinner BF. Teaching machines. Science 1958; 128: 969-977.

2. Crowder NA, Martin GC. Adventures in Algebra. London, English Universities Press. 1962.

3. Bitzer D, Lyman E, Easley J. The uses of PLATO: a computer controlled teaching system. Urbana, Coordinated Science Laboratory, University of Illinois, Report R-268. 1965.

4. Gordon M, Chandratilake M, Baker P. Low fidelity, high quality: a model for e-learning. Clin Teacher 2013; 10: $258-263$

5. Hartmann AC, Cruz PD. Interactive mechanisms for teaching dermatology to medical students. Arch Dermatol 1998; 134: 725-728.

6. Bell DS, Fonarow GC, Hays RD, et al. Self-study from web-based and printed guideline materials. Ann Int Med 2000; 132: 938-946.

7. Lau F, Bates J. Review of e-learning practices for undergraduate medical education.J Med Syst 2004; 28: 71-87.

8. Ellaway R, Masters K. AMEE Guide 32: e-Learning in medical education, Part 1: Learning, teaching and assessment. Med Teach 2008; 30: 455-473. 
9. Doherty I, McKimm J. E-learning in clinical teaching. BrJ Hosp Med 2010; 71: 44-47.

10. Taylor DC, Hamdy H. AMEE Guide 83: Adult learning theories: implications for learning and teaching in medical education. Med Teach 2013; 35: e1561-e1572.

11. Brinthaupt TM, Fisher LS, Gardner JG, et al. What the best online teachers should do. MERLOT J Online Learn Teach 2011; 7: 515-524.

12. Miller GE. The assessment of clinical skills/competence/ performance. Acad Med 1990; 65: s63-s67.

13. Ally, M. Foundations of educational theory for online learning. In: Anderson C, Elloumi F, Eds. Theory and Practice of Online Learning; 2nd Edn. Athabasca, Athabasca University Press, 2004; pp. 3-32.

14. Wenger E. Communities of Practice: Learning, Meaning, and Identity. Cambridge: Cambridge University Press, 1998.

15. Educause learning Initiative. (2009). 7 things you should know about Personal Learning Environments. URL: http://net.educause.edu/ir/library/pdf/ELI7049. pdf Date last accessed: March 5, 2014.

16. Attwell, G. The Social Impact of Personal Learning Environments. In: Wheeler S. Ed. Connected Minds, Emerging Cultures: Cybercultures in Online Learning. Charlotte, Information Age Publishing, 2009; pp. 119-137.

17. Drexler W. The networked student model for construction of personal learning environments: balancing teacher control and student autonomy. Australasia J Educ Tech 2000; 26: 369-385.
18. Väljataga $T$, Laanpere $M$. Learner control and personal learning environment: a challenge for instructional design. Interact Learn Environ 2010; 18: 277-291.

19. PLE project, University of Geneva. URL: http://ple. unige.ch/en/ Date last accessed: October 232014.

20. Attwell G. Personal Learning Environments for creating, consuming, remixing and sharing. In: Griffiths D, Koper R and Liber O., Eds. Service Oriented Approaches and Lifelong Competence Development Infrastructures. Proceedings of the 2nd TENCompetence Open Workshop. Available from http://dspace.ou.nl/bitstream/1820/1023/1/Proceedings_ TENC_Manchester_11-12jano7.pdf Date last updated: August 20 2007. Date last accessed: October 232014.

21. Sutherland, S. and Powell, A., CETIS SIG mailing list discussions, 9 July 2007. Available from www. jiscmail.ac.uk/cgi-bin/webadmin? $\mathrm{A} 2=$ indo707\& $\mathrm{L}=$ CETIS-PORTFOLIO\&F $=\& S=\& P=21742$ Date last accessed: October 232014.

22. Palange $P$, Busari J, Hare A, et al. Perspectives in medical education: signposts to the future in educating respiratory specialists. Eur Respir J 2012; 39: 520-524.

23. Palange P, Noel JL, Simonds AK. The European Respiratory Society: future directions in medical education. Eur Respir J 2011; 38: 498-499.

24. Fiedler SHD, Väljataga T. Personal Learning Environments: a conceptual landscape revisited. eLearning Papers 2013; 35: 1-16. URL: www. openeducationeuropa.eu/sites/default/files/asset/Indepth_35_2.pdf 